\title{
OBSERVACIONES SOBRE EL CONCEPTO DE OBEDIENCIA CIVIL Y OPINIÓN PÚBLICA EN TOMAS HOBBES Y JEAN-JACQUES ROUSSEAU.
}

\section{COMMENTS ON THE CONCEPT OF CIVIL OBEDIENCE AND PUBLIC OPINION IN TOMAS HOBBES AND JEAN-JACQUES ROUSSEAU}

\author{
Por: Vargas, Lucas Gamaliel. ${ }^{*}$ \\ Universidad Nacional del Nordeste \\ E-mail: lucasvargasga@gmail.com
}

Fecha de recepción: 29/03/2021

Fecha de aprobación: 25/04/2021

DOI: http://dx.doi.org/10.30972/ach.065607

\begin{abstract}
Resumen
El presente trabajo establece una relación entre dos pensadores de la Filosofía Política Moderna. Dicha relación está compuesta por los conceptos de Opinión y Obediencia cuyos aportes principales recaen sobre la noción de obediencia política en autores como Tomas Hobbes y Jean-Jacques Rousseau. En lo que respecta a las fuentes bibliográficas hemos seleccionado un texto de cada autor: El contrato social de Rousseau y el Leviatán de Hobbes. En relación a lo mencionado, hemos aludido a los posibles aportes que las prácticas de gobierno de la modernidad, emergidas de las estrategias de gobierno de la época, precisamente de la obediencia política, han brindado a la contemporaneidad.

Palabras clave: Opinión; Obediencia; Libertad; República; Soberano.
\end{abstract}

\footnotetext{
Abstract

This paper establishes a relationship between two thinkers of Modern Political Philosophy. This relationship is composed of the concepts of Opinion and

* El presente trabajo surge en el marco de la cátedra Filosofía Política en el año 2020

* Estudiante del Profesorado y la Licenciatura en Filosofía
} 
Abril 2021.

ISSN 2344-9934

Obedience whose main contributions lie on the notion of political obedience in authors such as Tomas Hobbes and Jean-Jacques Rousseau. As far as bibliographic sources are concerned, we have selected a text from each author: Social Contract by Rousseau and Leviathan by Hobbes. In relation to the aforementioned, we have alluded to the possible contributions that the practices of government of modernity, emerging from the strategies of government of the time, precisely from political obedience, have provided to the contemporaneity

Key words: Opinion; Obedience; Liberty; Republic; Sovereign.

\section{Cómo citar este artículo:}

APA: Vargas, L. G. (2021). Observaciones sobre el concepto de obediencia civil y opinión pública en Tomas Hobbes y Jean-Jacques Rousseau. Acheronta, № 6, 181-196. Recuperado de: (agregar dirección web)

\section{Introducción}

Nos proponemos como objetivo principal realizar un breve ensayo a modo de establecer una relación entre opinión y obediencia en el ámbito de la Filosofía Política. Para ello hemos seleccionado dos autores clásicos, a saber, Jean-Jacques Rousseau y Thomas Hobbes. En lo que respecta al entorno político filosófico del periodo de los siglo XVI-XVIII, encontramos autores que han trabajado sobre la preocupación política de la época y es aquella por cómo gobernar, en términos civiles, a la sociedad. Es por ello que, nuestro escrito, gira en torno a dicha problemática ya que la misma nos permite expresar nuestro objetivo primordial.

En el siglo XVI, el interés de La Boétie, al momento de escribir su ensayo titulado El discurso de la servidumbre voluntaria radica en pensar, cómo es posible la obediencia de un pueblo desde la servidumbre de este frente al tirano. Ya en La Boétie comienza a plantearse el concepto por la obediencia pero no en términos de superioridad, sino que se instala la inquietud frente a la idea de elegir voluntariamente obedecer en tiranía. $\mathrm{Y}$ es aquí donde, posteriormente a este siglo, pensadores como Spinoza, Hobbes y Rousseau mantienen no solo un interés gnoseológico o metafísico 
sino un alto compromiso moral, político y religioso, instalando así la problemática de obediencia política en la Filosofía Moderna.

Esta preocupación que despierta en pleno siglo XVI es la que toma forma en los siglos posteriores porque "se comienza a pensar que si hay obediencia al tirano, esta no puede ser voluntaria, y si hay obediencia voluntaria, el depositario, es decir, el soberano, no puede ser un tirano". (Apuntes, Filosofía Política, 2020) Es en este contexto donde nos detenemos con nuestro análisis. Ahora bien, hemos decidido diferenciar por autor para que quede lo suficientemente claro qué está entendiendo cada uno a la hora de hablar de opinión como de obediencia. Cabe destacar que no se pretende ser exhaustivos en el análisis de dichos conceptos, sino esbozar lo que, en general, ambos pensadores plantean respecto al tema.

Si tenemos en cuenta a Thomas Hobbes, en lo que respecta al primer apartado, identificaremos que propone dos tipos de obediencia. En primer lugar, encontramos la obediencia político-jurídica, la cual se fundamenta en el pacto de los súbditos con el soberano $y$, en segundo lugar, encontramos la obediencia de opiniones, que es aquella que se fundamenta bajo el gobierno de las mismas que se generan en la sociedad, ya sea desde los súbditos mismos o desde las instituciones a las que estos asisten.

Algo semejante ocurre en Rousseau, con la diferencia de que el ginebrino instala en la idea de individuo un fuerte compromiso ético-político de modo que sirviera de común ordenador y mantuviera la paz en la República. En lo que respecta a este autor, abordaremos desde sus conceptualizaciones preponderantes con vistas a una hipótesis que nos permita reflejar la relación entre los conceptos que hacen al objetivo de nuestro escrito y, en la medida que fuese posible, llegar a una conclusión que refleje el poderío religioso como político que, en general, es tenido en cuenta por ambos pensadores de cuando se trata de gobernar.

Cabe aclarar que, si bien tomaremos ciertos ejemplos e incluso ideas de Thomas Hobbes en el segundo apartado, los cuales consideramos relevantes a la hora de plasmar la idea rousseauniana en relación a la temática, no queremos caer en una comparación entre ambos pensadores, ya que no es el objetivo propuesto. Nos parece 
de suma importancia dicha aclaración porque, como es sabido, hay cierta similitud de ideas entre ambos escritores, sin embargo, Rousseau, al desarrollar la idea de religión civil se diferencia del filósofo inglés dando a entender que la idea que tenía Hobbes al pensar al Estado es, políticamente contraproducente.

\section{El estado natural y la legitimidad del poder soberano en Thomas Hobbes}

Hobbes entiende por obediencia al deber obligatorio que parte, por voluntad propia, de los súbditos en pos de humanizar la vida individual y social. Partiendo de la primera identificación de obediencia, entendemos que el autor tiene preferencia por evidenciar lo que se encuentra en la voluntad vital de cada hombre, es decir, en lo más instintivo de cada ser humano. Ahora bien, hemos decidido tomar como referencia, para expresar la noción de derecho natural al que refiere el autor, dos conceptos importantes: Vida y Libertad. Ambos conceptos son para el autor derechos naturales, son innatos tanto la idea de derecho natural a la vida como el derecho a la libertad, propios del individuo pasional, cuya idea de individuo que hasta la época no había sido tratada al menos desde lo político. A raíz de esto, presentado de una forma general, el autor asegura que la pasión solo puede ser guiada por el uso de razón. En este sentido creemos que el autor entiende el estado natural del hombre como una condición social y no como un animal político, tal como lo aludía Aristóteles.

Sin embargo el inglés detecta, en principio, un grave problema en la utilización de estos derechos naturales. Asegura que en la práctica de los individuos, surgida en la cotidianeidad de todo hombre, acarrean una lucha por subsistir en la tiranía por medios de supervivencia, ya sea, la tierra, el alimento, el trabajo, incluso el cuerpo, es decir, la vida. En este contexto es donde entendemos que Hobbes inserta el principio, basado en el cimiento de lo individual, de fijar un pacto para que no existiese, a saber, la guerra de todos contra todos. Y es aquí donde nace la condición política presentada por Hobbes, dicho de otra manera, es aquí donde surge el Estado o sociedad civil. Podemos citar lo siguiente: "[...] manifiesto que durante el tiempo en que los hombres viven sin un poder común que les obligue a todos al respecto, están en aquella 
condición que se llama guerra; y una guerra como de todo hombre contra todo hombre" (Hobbes, 1980, p.224). A raíz de la posibilidad de que existiese la guerra, el autor asegura que se pone en juego otro instinto pasional por mantenerse vivo, y es el de buscar la paz cuya naturaleza nace del miedo a la muerte.

En el momento que el hombre busca llevar a cabo la paz, es necesario que se haga bajo la normativa de un poder común, es decir, un pacto. Ahora bien, dicho pacto se basa en la transferencia del derecho ilimitado del estado de naturaleza, a una sociedad que impone leyes representadas en una única persona que reúne la voluntad de todos, a saber, el soberano. Dicha transferencia es entendida en pos de una defensa estable para todos. En este sentido, nace la obediencia siendo entendida como condición de obligación, dicho de otra manera, nace la obediencia políticojurídica. Una obligación que se corresponde de los súbditos al soberano y solo a él, ya que es este quien a su vez es el único que actúa de garantía ante el tratado paz.

Tal es así que la obediencia acarrea consigo, y en su modo de intervenir, ciertas prácticas que el autor destaca, por un lado, en tanto que son útiles para la conservación de la República, y por otro, para mantener la "libertad" de los derechos naturales de los hombres. Solo donde hay obediencia civil hay República. Podemos citar lo siguiente:

La prosperidad de un pueblo regido por una asamblea aristocrática o democrática no proviene de la aristocracia ni de la democracia, sino de la obediencia y concordia de los súbditos, ni florece el pueblo en una monarquía porque tenga un hombre derecho a gobernarle, sino porque aquél le obedece. (Hobbes, 1980, p.410)

Existe una cuestión de derecho de Libertad en el individuo que al momento que asume la obediencia de obligación, que es aquella que le aporta prosperidad al pueblo, dicho derecho toma forma en la sociedad asumiendo las normativas civiles. Podría pensarse que, al asumir la obediencia de obligación, el individuo se ve obligado a despojarse de sus derechos naturales, principalmente de su libertad, sin embargo, el hecho de asumir dicha obediencia no anula de manera absoluta el derecho de libertad, porque la libertad no solo que se mantiene en las relaciones sociales de los súbditos 
sino que se encuentra en situaciones que implican la conservación de la vida; por ejemplo, en situaciones límite o de peligro a las que los ciudadano se enfrentan.

Es por ello muy importante para el Soberano no romper el pacto en tanto que él debe la protección a la vida a sus súbditos, ya que sin ella, estos pueden tender a la desobediencia. Es en este sentido que se entiende a la obediencia de obligación ya que existe una correspondencia de un deber de ambas partes, tanto de los súbditos como del Soberano. Nos parece interesante destacar esta cuestión, no solo porque las acciones que emergen de las situaciones límites marcan el seno de lo jurídico y su estado de excepcionalidad política, sino porque es ahí donde el autor sienta, en sentido general, la obediencia en un segundo sentido, cuya explicación se dará en el desarrollo porvenir.

En definitiva, y a modo de cierre de la primera y sencilla identificación de obediencia, es notoria su relación no solo con el deber sino con la Libertad de los individuos. Existe una libertad de subordinación a las leyes civiles, propias de la República, pero también existe una "libertad" que se manifiesta por fuera de tales leyes, es decir, en la protección de la vida en situaciones absolutamente límites; y es ahí donde recaen las opiniones, por ejemplo, sobre las normativas de las leyes civiles de la República. Dichas normativas anteceden lo político desde el punto de vista de lo jurídico, sin embargo, es el poder político quien subordina al jurídico para el despliegue de sí mismo.

Lo dicho hasta el momento refleja que en las situaciones límites el miedo es un hábito natural que se resiste a ser modificado, dicho de otra manera, el miedo, y en especial el miedo a la muerte violenta, es un instinto natural que hace de fundamento al pacto social, ya que es el que se encuentra en la base de los derechos naturales.

El segundo tipo de obediencia, que no aparece explicitado en el tratado de Hobbes pero que podemos reconstruir a partir de algunas ideas que expresa a lo largo de la obra, tiene que ver con el gobierno de la opinión. Gobernar las opiniones es muy importante para sostener el poder por parte del soberano, es decir, mantener la paz y 
la concordia de la República, y a su vez, mantener un orden sobre aquellas inclinaciones de preferencia cristiana establecidas en los mandamientos.

Para lograrlo, el soberano debe influir en los individuos a través de la instrucción. Es por ello que en el capítulo XVII despliega la idea de que este tiene el deber de instruir al pueblo en las leyes y prerrogativas que establece para el funcionamiento de la sociedad, para que ningún súbdito se encuentre en desconocimiento de ellas y pueda así caer en opiniones contrarias a las ya establecidas, lo cual puede desembocar en rebelión o desobediencia. En palabras de Hobbes, no se trata solo de un deber, sino también de "su beneficio y seguridad contra el peligro que en su persona natural puede acecharle por una rebelión". (Hobbes, 1980, p.410)

La necesidad de que el pueblo obedezca también a partir de las opiniones tiene su asiento en que, si se permite que opiniones contrarias a las leyes deambulen entre los súbditos, se corre el riesgo de que estas pasen a ser acciones. Es allí donde se materializa la rebelión. En este sentido, cualquier regla no prescripta por el soberano puede ser tomada solo como consejo, pero nunca debe acatarse como ley, mucho menos si es contraria por muy buena que le parezca. El autor inglés expresa:

[...]no puede en este caso acatarlo en sus actos ni en su discurso con otros hombres, aunque pueda sin culpa creer a sus maestros particulares y desear tener la libertad de llevar a la práctica su consejo, y que este fuere públicamente recibido como ley, porque la fe interna es por su propia naturaleza invisible y, por consiguiente, está exenta de toda jurisdicción humana, mientras que las palabras y acciones que proceden de ella son como rupturas de nuestra obediencia civil, injusta tanto ante Dios como ante el hombre. (Hobbes, 1980. p, 574)

Uno de los ámbitos que Hobbes señala como el germen donde dichas opiniones funestas aparecen son las Universidades. En este punto menciona que "el poder del Papa fue siempre sostenido contra el poder de la República, principalmente por las Universidades, y que las doctrinas mantenidas por tantos predicadores contra el poder soberano del rey" (Hobbes, año 1980. p, 415) son razones más que suficientes para 
Abril 2021.

ISSN 2344-9934

controlar lo que en ellas se enseña. En ellas se encuentra la juventud, quien debe ser orientada hacia las leyes del soberano y no influida por otros principios que no sean los de la sociedad civil. La obediencia en el ámbito de las opiniones es importante, porque de ellas dependen el discurso y las acciones. Opiniones contrarias al soberano pueden desembocar en levantamientos contra su poder.

Llegado este punto, vemos con claridad que existe otra entidad que puede lograr un poder semejante al del soberano: Ia Iglesia. Solo la Iglesia puede influir en las conciencias, en las opiniones; y, por ello, puede tornarse peligrosa para el soberano si intenta detentar un poder que no le corresponde. Hobbes, en el capítulo XLII, despliega una larga serie de argumentos para dejar en claro que el poder eclesiástico reside, junto con el poder político, en la persona del soberano. Explica que el soberano es también pastor de la comunidad y que detenta ambos poderes, el político y el eclesiástico, y que delega el segundo en los ministros de la Iglesia. Establece que hay una jerarquía, donde el soberano está en la cúspide y donde el clero, y con ella el Papa, se subordinan ante el rey. Es decir, destierra toda idea de que haya una conexión directa entre la Iglesia y Dios, lo cual resulta conveniente para el soberano y le resta poder al Papa. El soberano viene a ser al Estado, incluido en él el clero, lo que el alma al cuerpo. Es interesante la argumentación de Hobbes, la cual creemos se resume en el siguiente fragmento:

Desde esta consolidación del derecho político y eclesiástico en los soberanos cristianos es evidente que estos tienen sobre sus súbditos toda forma de poder que pueda darse a un hombre para el gobierno de los actos externos de los hombres, tanto en política como en religión, y que pueden dictar las leyes que juzguen oportunas para el gobiernos de sus propios súbditos, tanto en cuanto son República como cuanto son Iglesia, pues Estado e Iglesia pertenecen los mismos hombres. (Thomas Hobbes, año 1980. $p, 597)$

Con esta idea Hobbes encierra en el soberano tanto la autoridad política como la religiosa, como alma de la comunidad. De este modo no reconoce el poder del clero como independiente, sino que logra subordinarlo al Estado, dejando en claro que es el 
soberano quien gobierna la sociedad tanto desde lo político-jurídico como sobre las conciencias de los súbditos. Es en este punto donde queremos resaltar que el Soberano garantiza la paz del Estado, de ser necesario con violencia, para evitar que los súbditos no caigan en un estado de desobediencia y, a su vez, el Soberano, "refleja el poder de la soberanía y la discrecionalidad del Estado en el que pensaba Hobbes" (Apuntes Filosofía Política 2020)

\section{De la libertad natural a la subordinación de la voluntad general en Jean-} Jacques Rousseau

Si partimos de una preocupación de los autores seleccionados, es evidente que la Libertad del hombre es una cuestión inicial en el poder político. Sin embargo, y siendo un factor infaltable para la conformación del Estado, la noción de libertad es un condimento "secundario" en el contexto civil: "[...] lo que el hombre pierde por el contrato social es su libertad natural y un derecho ilimitado a todo cuanto le apetece y puede alcanzar; lo que gana es la libertad civil y la propiedad de todo lo que posee" (Rousseau, 2007, p.50). Es decir, es la obediencia al poder político lo que define la Libertad . Pero antes de preguntarnos qué tipo de obediencia o incluso qué libertad subyace en la subordinación a la obediencia política, quisiéramos destacar que si hay un representante político de la época a quien Rousseau cuestiona es, en gran medida, al filósofo inglés Thomas Hobbes. Nuestro pensador inglés supo, y muy bien, como lo hemos visto, cuáles riesgos corría el Estado si no se gobernaba a los súbditos de la mayor y mejor manera posible, preocupación que se encuentra hasta en el mismo Rousseau.

Ahora bien, Rousseau cuestiona a Hobbes al afirmar que el estado de naturaleza que él define no es en realidad el verdadero estado de naturaleza. Y esto no es una cuestión menor, ya que las cualidades que el hombre adquiere al dejar el estado de naturaleza y pasar a la conformación del agrupamiento social, según Rousseau, va a influir de manera directa en la conciencia del hombre. En este sentido, lo que evidencia Rousseau, con un carácter provocador, no es solo la condición de 
Abril 2021.

ISSN 2344-9934

suma individualidad que el hombre acarrea consigo al nacer, sino también la noción de comunidad con la que comienza a trabajar el autor.

Si tenemos en cuenta lo que describe del estado de naturaleza del hombre, asegura que el mismo se encuentra bajo la tutela de los instintos, la espontaneidad de la naturaleza, las pasiones, etc. lo cual no lo hace pensar más que en sí mismo. De aquí nace lo que podemos establecer como la desigualdad entre los hombres, por un lado, y los males sociales, por otro. Rousseau lo va a expresar de la siguiente manera: "Pero el orden social es un derecho sagrado y sirve de base a todos los demás. Sin embargo, este derecho no viene de la Naturaleza; por consiguiente, está, pues, fundado sobre convenciones. Se trata de saber cuáles son estas convenciones" (Rousseau, 2007, p.36).

Podría pensarse que Rousseau no solo pensaba en el orden social de su época, sino también en el de su pasado, es por ello que el problema que se le presenta al autor parece ser el siguiente: ¿cómo lograr garantizar, a un mismo tiempo, la seguridad colectiva de los individuos de una sociedad, como así también la libertad individual de todos los ciudadanos de la República? En otras palabras, cómo hacer que la opinión (individual o pública) genere la menor discordia posible, o incluso nula, en lo que respecta a la obediencia hacia el poder político, que es el que busca, mediante la voluntad general, el bien común de todos.

Rousseau (2007) señala que, en el contrato social, si nos enfrentamos a quienes se oponen a él, su oposición no invalida el contrato, sino que, a lo sumo, impide que sean comprendidos en él. Esto es importante ya que remarca la nulidad de validez de las opiniones en general, en relación con el interés común. El autor asegura que "La censura mantiene las costumbres, impidiendo que se corrompan las opiniones, conservando su rectitud mediante sabias aplicaciones y, a veces, hasta lijándolas cuando son inciertas"(Rousseau, 2007, p.153).

En este sentido, nuestro autor es claro al aseverar que la solución al mencionado problema se resuelve con el pacto. Ahora bien, queda dejar en claro en qué consiste dicho pacto: 
Este acto produce inmediatamente, en vez de la persona particular de cada contratante, un cuerpo moral y colectivo, compuesto de tantos miembros como votos tiene la asamblea, el cual recibe de este mismo acto su unidad, su yocomún, su vida y su voluntad. (Rousseau, 2007, p. 46)

El pacto social para Rousseau hace emerger un hombre moralmente nuevo, cuya finalidad constituye la base de toda la sociedad política y en la cual los ciudadanos deben ceder sus derechos naturales para el bienestarde la comunidad. Para que esto se dé de tal manera, según el autor, es necesario establecer las convicciones del pacto. Si partimos de lo que el ginebrino expone, comienza dejando en claro que existen dos voluntades: la voluntad general, por un lado, y la voluntad individual o particular, por otro. Y en este sentido Rousseau es claro al rectificar que la voluntad general lo que busca es, no solo mantener la libertad de los ciudadanos en lo que respecta en obediencia para sí mismos, sino que, a su vez, asegura que dicha voluntad tiene, por definirlo de alguna manera, un ideal que se rige por el interés de todos los individuos; y, por lo tanto, el individuo al formar parte de la conformación de dicho contrato, no acciona de otra manera que gracias a su propia voluntad.

La primera y más importante consecuencia de los principios anteriormente establecidos es que la voluntad general puede dirigir por sí sola las fuerzas del Estado según el fin de su institución, que es el bien común; porque si la oposición de los intereses particulares ha hecho necesario el establecimiento de las sociedades, el acuerdo de estos mismos intereses es lo que lo ha hecho posible. Esto es lo que hay de común en estos diferentes intereses que forman el vínculo social; y si no existiese un punto en el cual se armonizasen todos ellos, no hubiese podido existir ninguna sociedad. Ahora bien; sólo sobre este interés común debe ser gobernada la sociedad. (Rousseau, 2007, p.55)

Como se mencionó en líneas anteriores, existe una cuestión que el autor alude, que no pretendemos desarrollar ni entrar en detalles en este escrito, pero que nos parece preciso mencionar: el interés por el cual el individuo se mantiene en el cuerpo social. Es el interés lo que define con qué tipo de voluntad trazar sus relaciones 
Abril 2021.

ISSN 2344-9934

sociales; por lo tanto, si nos quedamos con el interés de la voluntad particular, es claro que se generan, por naturaleza, preferencias individuales. Ahora bien, volviendo a lo que respecta a la voluntad general, concepto preponderante en la obra que trabajamos, nos parece importante destacar el grado de veracidad que esta voluntad toma en la sociedad, específicamente en el momento de realizar el contrato social. Rousseau asegura que la voluntad no puede corromperse

[...] porque la voluntad es general o no lo es; es la del cuerpo del pueblo o solamente de una parte de él. En el primer caso, esta voluntad declarada es un acto de soberanía y hace ley; en el segundo, no es sino una voluntad particular o un acto de magistratura; es, a lo más, un decreto.(Rousseau, 2007, p.56)

En este sentido podríamos asegurar que, si bien la voluntad general tiene el carácter de ser recta hacia el bienestar del pueblo, es este quien tiende a la tiranía y, por lo tanto, es claro que la voluntad de todos no es la voluntad general; cuya finalidad no es el interés privado sino, justamente, el interés común. Creemos que se dejó lo suficientemente en claro en qué consiste cada voluntad, lo cual, nos permite pasar al siguiente paso, a saber, cómo se relacionan dichas voluntades en el objetivo propuesto del apartado.

La voluntad general no depende, cuantitativamente del pueblo, sino de su interés, el cual es siempre bueno, verdadero. Dicho en otros términos, el contrato social dispone un poder absoluto mediante la voluntad general que pone al servicio de la Soberanía a cada uno de sus miembros. Ahora bien, es importante mencionar que, según el autor, para que el Estado se mantenga sin que las opiniones alteren su orden, es necesario "que no haya ninguna sociedad parcial en el Estado y que cada ciudadano opine exclusivamente según su propio entender [...]" (Rousseau, 2007, p.56).

A partir de lo mencionado se puede ver el carácter de suma individualidad en el que enfatiza Rousseau. Es por ello que el autor remarca en la necesidad de que pueda renacer un tipo de hombre moral mediante la voluntad general. Y es aquí donde nuestro el ginebrino sienta la base de todo origen de la conformación del Estado, asegurando que, en el interior de este se encuentra la Religión, es decir, en términos 
generales, la Iglesia. Dicho en otros términos, es en el individuo ético-político donde Rousseau instala la idea de religión civil.

En este sentido, podemos trazar una semejanza con Hobbes cuando el inglés analiza, mediante cierta estratégica de gobierno sobre las conciencias de los súbditos, no incluir a la Iglesia en el origen del Estado, pero sí mantener un gobierno por sobre las opiniones que se generan en la misma. Es decir, mientras que Hobbes entiende la necesidad de disciplinamiento de las instituciones, en específico, las universidades, la Iglesia, Rousseau se atreve a plantear la noción de religión civil, cuya virtud no solo da origen al orden político sino que permite al autor dar un carácter fundacional para el Estado a la Religión. A nuestro entender, Hobbes es más cauteloso y logra subordinar el poder del clero al poder político porque entiende la suma importancia que la Iglesia tendría sobre el Estado, sin embargo, Rousseau, políticamente hablando, es más eficaz en cuanto que mantiene al individuo bajo las normativas de las prerrogativas religiosas como también políticas.

Sin perder de vista la virtud que el ginebrino le otorga al contrato social, se llega a aseverar que este actúa de garantía del Estado y de todos sus contratantes, e incluso, a los que pretendieron actuar en vista de la voluntad individual. Por lo tanto, se necesita la subordinación del individuo a la voluntad general cuya garantía no deja caer al ciudadano, moralmente hablando, en un ser injusto.

En efecto; cada individuo puede como hombre tener una voluntad particular contraria o disconforme con la voluntad general que tiene como ciudadano; su interés particular puede hablarle de un modo completamente distinto de como lo hace el interés común; su existencia, absoluta y naturalmente independiente, le puede llevar a considerar lo que debe a la causa común, como una contribución gratuita, cuya pérdida será menos perjudicial a los demás que oneroso es para él el pago, y considerando la persona moral que constituye el Estado como un ser de razón, ya que no es un hombre, gozaría de los derechos del ciudadano sin querer llenar los deberes del súbdito, injusticia cuyo progreso causaría la ruina del cuerpo político. (Rousseau, 2007, p.49) 
Si tenemos en cuenta lo analizado hasta el momento, es notoria la necesidad de obediencia hacia la voluntad general por las suficientes razones presentadas. Ahora bien, queda dejar en claro, en el caso de ser necesario, qué piensa expresamente el autor con respecto a las opiniones. Para ilustrar dicha idea, creemos que es conveniente insertar una cita que, a nuestro entender, nos permita concluir con el objetivo propuesto:

Los súbditos no tienen, pues, que dar cuenta al soberano de sus opiniones sino en tanto que estas opiniones importan a la comunidad. Ahora bien; importa al Estado que cada ciudadano tenga una religión que le haga amar sus deberes; pero los dogmas de esta religión no le interesan ni al Estado ni a sus miembros sino en tanto que estos dogmas se refieren a la moral y a los deberes que aquel que la profesa está obligado a cumplir respecto de los demás. Cada cual puede tener, por lo demás, las opiniones que le plazca, sin que necesite enterarse de ello el soberano; porque como no tiene ninguna competencia en el otro mundo, cualquiera que sea la suerte de los súbditos en una vida postrera, no es asunto que a él competa, con tal que sean buenos ciudadanos en ésta.(Rousseau, 2007, p. 163)

Es importante que cada individuo mantenga sus acciones bajo el dogma de su religión sin que estos alteren el interés del Estado, porque de lo contrario el soberano tiene el poder, es decir, el derecho de examinar el fundamento de las opiniones e incluso las acciones de los ciudadanos. Las opiniones no son un peligro para nadie, ni siquiera para el Estado, mientras no alteren el interés común, es decir, el bienestar social por el cual se rige la Soberanía y que cuya garantía se centra por la voluntad general. Claro está que aquello que no irrumpe en el interés del Estado ni atenta contra el bienestar social, cumpliendo las leyes de la República, queda a merced del súbdito en su conciencia, y solo en él. Por lo tanto, como señala y cree el autor, mediante el contrato social es posible garantizar la seguridad colectiva de los individuos de una sociedad, así como la libertad individual de todos los ciudadanos de la República. 


\section{Conclusión}

Teniendo en cuenta nuestro principal objetivo, podemos afirmar que en el presente trabajo se ha cumplido con lo establecido. Ya que, en relación con las conceptualizaciones presentadas, no solo hemos aludido a las dos nociones de obediencia que presenta Hobbes sino al desarrollo de la hipótesis presentada en Rousseau. En este sentido, podemos hacer notorio que el gobierno de la opinión pública como de obediencia civil es depositado en la figura del Soberano.

La preocupación que Hobbes tenía a la hora de plantear que no solo se debía gobernar de manera político-jurídica al Estado sino que, a su vez, el poder del soberano debía llevar las riendas sobre las opiniones de los súbditos, es decir, la de gobernar la conciencia de estos, se traslada en Rousseau de manera diferente, pero a nuestro entender más consolidada en vista a la comunidad. Dicho de otra manera, lo que Hobbes pretendió para el poder soberano de la época, Rousseau lo pone en evidencia mediante la formulación del concepto religión civil de modo que esta sirviera al Soberano como instrumento sobre sus súbditos, y al autor para comenzar a plantear un análisis de lo social en términos de comunidad.

La preocupación de la modernidad acerca de cómo gobernar tiene como principal objetivo mantener la vida no solo de los individuos, sino al cuerpo social político al que estos pertenecen. Y en este sentido los autores son claros en expresar la importancia de subordinar a los ciudadanos en pos de mantener un orden social y así dar garantía de vida al cuerpo de dicho orden. Sin embargo, hay una cuestión central, que podemos extraer de lo desarrollado, y es que el poder que mantiene el soberano sobre sus súbditos, implica también el derecho a dar muerte. Esta cuestión expresamente moderna adquiere diferente formato en la contemporaneidad mediante diferentes prácticas de disciplinamiento. En relación con esto, creemos que lo desarrollado en este escrito nos ayuda a pensar, desde lo político, la importancia del nacimiento de la Biopolítica, cuyo principal referente es Michel Foucault. El interés que este filósofo pone en cuestión sobre este tema es pensar el poder soberano que precede a la Biopolítica en relación a esta. 
Abril 2021.

ISSN 2344-9934

Por lo tanto, podemos concluir que a partir de las observaciones de los conceptos obediencia y opinión los Estados comenzaron a poner en marcha en la modernidad ciertas estrategias políticas para dar forma a una práctica de gobierno que luego serían reformuladas con el nacimiento de la Biopolítica.

\section{Bibliografía:}

Thomas H. (1980) Leviatán. (C. MOYA y A.ESCOHOTADO. Trad.) Antonio Escohotado.

Rousseau, J.J. (2007). El Contrato Social. (F. de los Ríos. Trad) España: Esposa Calpe, S. A. 